\title{
EVOLUTION OF NON-TREATED RESTLESS LEGS SYNDROME
}

\author{
Raimundo Nonato Delgado Rodrigues', Aída Alexandra Alvim de Abreu e Silva Rodrigues², \\ Jorge Faber ${ }^{3}$, Jeana T. Corso 3 , Thaisa F. Peixoto ${ }^{4}$
}

\begin{abstract}
Purpose: The primary concern of this study is to evaluate the clinical course of restless legs syndrome (RLS) in a group of patients who refused treatment. Method: This study compares the outcome of a group of RLS patients after one year without any specific treatment. The International Restless Legs Syndrome Scale (IRLS) was applied at baseline (irls_1) and after one year (irls_2). The patients answered a simple questionnaire for the evaluation of possible environmental or life habit changes after one-year evolution. Serum ferritin was determined at baseline. An improvement index (\%improvement) was established through the formula: irls 1irls_2/irls_ $1 \times 100$. Results were compared and a correlation analysis performed. Results: A negative significant correlation was found between the patientsi age and irls_2 $(r=-0.9 p=0.0018)$ and between \%improvement and irls_2 $(r=-0.88 p=0.0039)$. A positive and significant correlation was determined between \%improvement and age. There was only a marginally significant correlation between serum ferritin and ilrs_2 $(r=-0.7 p=0.052$ ). No significant changes were found in the other elements analyzed. Conclusion: A favorable outcome was found in this group of RLS patients after one year evolution without treatment. The outcome was positively influenced by the patientsi age.
\end{abstract}

KEY WORDS: restless legs syndrome, IRLS, outcome, clinical course, long-term evolution, treatment, age.

\section{Sindrome das pernas inquietas: evolução após um ano sem tratamento}

Resumo - Objetivo: O objetivo deste estudo é avaliar a evolução de oito pacientes com diagnóstico de síndrome das pernas inquietas (SPI) após doze meses sem tratamento. Método: Estudo de coorte, retrospectivo, consistindo na aplicação da escala de gravidade da SPI (IRLS), de questionário para avaliação de mudanças ambientais ou de hábitos de vida e dosagem de ferritina sérica. Realizada comparação da pontuação IRLS obtida na consulta inicial (irls_1) e após doze meses de evolução (irls_2) e estabelecido um índice de melhora percentual (\%melhora=irls_1 - irls_2 / irls_ $1 \times 100$ ). Análise de correlação dos dados obtidos. Resultados: Foi demonstrada correlação negativa e significativa entre a idade e a irls_2 ( $r=-0,9$ e $p=0,0018)$ e entre \%melhora e irls_2 $(r=-0,88$ e $p=0,0039)$. Encontrou-se correlação positiva e significativa entre \%melhora e a idade. Houve apenas correlação negativa marginalmente não-significativa entre a dosagem de ferritina sérica e ilrs_2 $(r=-0,7$ e $p=0,052)$. Conclusão: Neste grupo demonstrou-se evolução favorável da SPI após doze meses que se correlacionou positivamente com a idade dos pacientes, não tendo sido influenciada aparentemente por hábitos de vida ou mudanças ambientais.

PALAVRAS-CHAVE: síndrome das pernas inquietas, IRLS, curso clínico, tratamento, idade.

Restless legs syndrome (RLS) is a neurological disorder characterized by an urge to move the limbs, usually lower limbs, sometimes associated with paresthetic sensations, emerging or worsening with rest or inactivity, which symptoms become worse at dusk, with prevalence of 5.5\% of the general population ${ }^{1,2}$. However, the practice shows that fewer patients are diagnosed and treated than sug- gested by studies on the prevalence of RLS ${ }^{3}$. Among the reasons for this finding is worth mentioning the low recognition of the clinical condition by the medical population $^{4}$, which can lead to diagnostic errors ${ }^{5}$. On the other hand, patients may also collaborate for the under-diagnosis by not realizing or not recognizing the pathological condition that needs treatment ${ }^{6}$.

\footnotetext{
'MD, MSc, PhD, Neurologist, Sleep Disorders Center, Hospital Universitário de Brasília, University of Brasília, Brasília DF, Brazil; ${ }^{2}$ MD, PulmonologistSleep Disorders Center, Hospital Universitário de Brasília, University of Brasília, Brasilia DF, Brazil; ${ }^{3} \mathrm{DDS}, \mathrm{MSc}$, PhD, Orthodontist in Private Practice. SCN Brasília Shopping sala 408, Brasilia DF, Brazil; ${ }^{3}$ Fellow Neurology Department, University of Brasília, Campus Darcy Ribeiro s/n, Brasília DF, Brazil; ${ }^{4}$ Fellow Neurology Department, University of Brasília, Campus Darcy Ribeiro s/n, Brasília DF, Brazil.
}

Received 11 August 2008, received in final form 6 November 2008. Accepted 11 December 2008. 
Indeed, RLS diagnosis is not easy. A recent population study showed that a significant number of patients do not seek for medical aid due to the motor condition, but rather because of consequences of RLS such as insomnia or drop on the quality of life $\mathrm{f}^{3,4}$. The diagnostic difficulties are exacerbated due to the lack of objective reference laboratory testing so far ${ }^{4}$. Moreover, even in specialized centers, the interrogation of patients many times collaborates very little for the correct diagnosis because individuals often have difficulty in describing the symptoms, which may even be confused with vascular and positional anomalies or even with psychic anxiety ${ }^{7}$. The presence of important genetic component whose expression may be delayed or temporally anticipated at every generation is another important issue to be considered ${ }^{8,9}$. The therapeutic management of this condition may be also subjected to discussion since not all patients require medical treatment ${ }^{4,10}$. All these issues, however, become even more relevant as the natural history of RLS has not been adequately described so far. In fact, there are only a few studies in literature where this is properly assessed, especially concerning the moderate or mild forms $\mathrm{s}^{4,6}$.

This study was conducted to investigate the course of RLS after twelve months of diagnosis in eight patients who, for several reasons, preferred not to undergo the pharmacological treatment proposed. Possible environmental, medication or life-style changes that might have influenced the evolution were also evaluated.

\section{METHOD}

Eight patients who fulfilled the international criteria for the clinical diagnosis of RLS were included in this study, being $5 \mathrm{fe}-$ male (62\%). All of them, after the diagnosis, made the decision not to follow any treatment. Patients had mean age of 50.8 \pm 17.4 years and came primarily from the middle-upper class. As additional inclusion criteria, there should not be a prior history of recent surgery, pregnancy, known disorders of renal function, no relevant association to another sleep disorders (sleep apnea syndrome, narcolepsy, for example) nor extrapyramidal diseases or use of drugs related to the treatment or known for inducing movement disorders (antidepressants, dopaminergic, neuroleptic, benzodiazepine, anticonvulsants or opioid agents) or use of ferric compounds in the six months prior to admission in the study.

After the clinical diagnosis of RLS, the patients had responded a Portuguese version of the International Restless Legs Syndrome Rating Scale (IRLS) ${ }^{11}$ to determine the severity of the clinical condition.

As part of the RLS diagnosis process, the serum iron and ferritin contents, as well as the transferrin saturation index were determined. Additionally, the full blood count and the erythrocyte sedimentation rate were performed. It was avoided collecting blood samples during the menstrual period. In this study, only the serum ferritin content was considered.
Table 1. Questionnaire: evolution after twelve months.

Were there any changes in the past year in relation to any of the following aspects of your life?

(Identify how was it 1 year ago and how is it now, if possible)

1. Ingestion of alcohol

2. Use of tobacco

3. Alimentary habits (caffeinated beverages)

4. Use of new medication

5. Blood donation

6. Work in shifts

The participants were evaluated in consultation between July and November 2006. All were contacted by phone by two of the authors (JTC and TFP) during December 2007. This time, the application of the IRLS was once again conducted and the patients were asked to reply a short questionnaire covering about possible changes in some aspects of their lives, habits or environment that could have influenced the evolution of RLS (Table 1).

Patients were included in the research after informed consent on the purposes of the study and approval by the ethics institutional committee.

In order to assess the improvement on the IRLS scores objectively, an arbitrary index (\% improvement) was considered, being calculated based on the formula: initial IRLS value (irls_1) minus the IRLS value after twelve months (irls_2), with results being divided by the irls_1 value. The final result was expressed as percentage.

The data were analyzed using the SAS V.8.1. software. The descriptive statistics of the dependent and independent variables were obtained. A Student paired t test was applied to test the hypothesis that there was no difference between IRLS at baseline and after 12 months without treatment. To access the relationship of serum ferritin and age at baseline, IRLS at the two different moments, and percentage of clinical improvement between these two moments, a correlation analysis was performed (Pearsonis correlation test). The level of significance was established at $5 \%$.

\section{RESULTS}

The descriptive data of this population can be found in Table 2. One of the individuals reported to have started "treatment for anxiety" in the period but, unfortunately, he was unable to report the name of the drug or dosage used.

During the study period, the patients reported no significant difference in their life habits concerning consumption of alcohol, tobacco, caffeinated beverages, blood donations or shift-work.

The IRLS questions answered in the initial consultation revealed that six patients $(75 \%)$ had scores that characterized severe RLS $(>21)$. The group of eight patients showed 
Table 2. Descriptive data of the population studied.

\begin{tabular}{cccccccc}
\hline Case & $\begin{array}{c}\text { Age } \\
\text { (years) }\end{array}$ & $\begin{array}{c}\text { RLS } \\
\text { onset }\end{array}$ & $\begin{array}{c}\text { New } \\
\text { medication }\end{array}$ & $\begin{array}{c}\text { Ferritin } \\
\mathrm{ng} / \mathrm{mL}\end{array}$ & irls_1 & irls_2 & Improvement\% \\
\hline 1 & 25 & 7 years & no & 38.3 & 18 & 18 & 0 \\
2 & 54 & 6 years & no & 215 & 24 & 7 & 70.8 \\
3 & 30 & 14 days & sinvastatin & 51.8 & 38 & 21 & 44.7 \\
4 & 56 & 5 years & no & 99.2 & 26 & 9 & 65.9 \\
5 & 41 & 12 years & trazodone & 17.9 & 29 & 12 & 58.6 \\
6 & 66 & 10 years & no & 66.1 & 34 & 7 & 79.4 \\
7 & 59 & 6 years & "anxyolitic" & 132 & 36 & 0 & 100 \\
8 & 75 & 10 years & enalapril & 212 & 8 & 0 & 100 \\
\hline
\end{tabular}

irls_1, initial IRLS score; irls_2, IRLS score after twelve months; \%improvement, irls_1 - irls_2 / irls_1 1 100

Table 3. Results of the correlation test (Pearson).

\begin{tabular}{lcccccc}
\hline & & Ferritin & irls_2 & irls_1 & \% improvement & age \\
\hline Ferritin & r & - & -0.70250 & -0.47557 & 0.62015 & 0.67068 \\
& $\mathrm{P}$ & - & 0.0520 & 0.2336 & 0.1009 & 0.0687 \\
irls_2 & $\mathrm{r}$ & - & - & 0.26186 & -0.88012 & -0.90864 \\
& $\mathrm{P}$ & - & - & 0.5310 & 0.0039 & 0.0018 \\
irls_1 & $\mathrm{r}$ & - & - & - & 0.03594 & -0.25430 \\
& $\mathrm{P}$ & - & - & - & 0.9327 & 0.5434 \\
\% improvement & $\mathrm{r}$ & - & - & - & - & 0.89529 \\
& $\mathrm{P}$ & - & - & - & - & 0.0026 \\
\hline
\end{tabular}

irls_1, initial IRLS score; irls_2, IRLS score after twelve months; \% improvement: irls_1 - irls_2 / irls_ $1 \times 100$.

initial average score of $26.6 \pm 10.0$ and, after twelve months without treatment, 9.25 \pm 7.6 . This difference was significant with $p=0.0028$. None of the patients at the end of the study had scores higher than 21.

The average time elapsed from the initial onset of RLS symptoms until the moment of consultation was 7 years.

The dosage of serum ferritin showed average of $104 \pm 76.2 \mathrm{ng} / \mathrm{mL}$ (normal range: $29-300 \mathrm{ng} / \mathrm{mL}$ ). Only two patients had serum ferritin below $50 \mathrm{ng} / \mathrm{mL}$.

The Pearson test showed a significant negative correlation between age of the population and the final values of the IRLS scores ( $r=-0.9 p=0.0018)$ and also between the improvement percentage and the irls_2 value $(r=-0.88$ $p=0.0039$ ). A significant positive correlation was found between the improvement percentage and age of the patients ( $r=0.89$ and $p=0.0026)$. This is equivalent to say that the older patients improved more during the twelvemonth period than younger patients (Table 3).

On the other hand, there was a negative correlation, but only marginally significant between serum ferritin and irls_2 values $(r=-0.7 p=0.052)$.

\section{DISCUSSION}

Most studies seem to suggest that the RLS presents a chronic natural course that tends to worsen with age until at least the age of 60 years ${ }^{6}$. On the other hand, there may be total remission of symptoms, even for a few months only, in up to $15 \%$ of cases, regardless of the therapy. Indeed, the literature recognizes that the long-term evolution is still unknown mainly in the mild to moderate forms ${ }^{3,6,7}$. The RLS patients with severe clinical course are, however, more easily diagnosed in primary care settings ${ }^{5}$.

On the other hand, it is known that patients with RLS often do not seek medical aid despite presenting intense symptoms ${ }^{6}$, and even when they do, they may still be under-diagnosed, since the RLS, out of specialized centers, is usually not recognized or considered as a significant health disorder ${ }^{4}$. In a recent study, Walters et al. reported that in a cohort of 140 RLS patients interviewed, $22 \%$ did not believe that they had a treatable condition ${ }^{12}$.

The patients included in this study reported motor symptoms characteristic of RLS. All patients belonged to the middle-upper class, and were mostly professionals and civil servants, with excellent educational level. 
Moreover, $75 \%$ of them had severe RLS score range and had motor complaints for 7 years on average, which, at least in theory, suggested a significant impact on daily life. Nevertheless, after the initial diagnostic workup, they refused any pharmacological treatment and did not return to subsequent consultations, giving several excuses. In the study conducted by Walters et al. $9 \%$ of the patients also gave several excuses for not seeking early treatment ${ }^{12}$.

Despite the refusal of treatment, when contacted approximately twelve months after the diagnosis, all patients but one reported significant improvement expressed in the drop of the IRLS scores $(p=0.0028)$, two of them being totally asymptomatic. This finding is interesting, since it by far surpasses the "few months" of remission reported in literature ${ }^{7,12}$.

The explanation of these results certainly cannot be found in changes in lifestyle or environment, at least on items evaluated, since there were no reports of significant change in the consumption of alcohol, tobacco, caffeinated beverages, blood donations or shift-work ${ }^{1,6}$.

No specific medication for RLS was used during the study period. One of the patients, however, used trazodone that may have contributed for sleep induction although not considered useful in the treatment of traditional forms of RLS. Similarly, it is not possible to analyze objectively the influence of the "anxiolytic" treatment used by another individual from the group since we have no details concerning the type of substance used or the dosing regimen or frequency.

The results of this study show a significant negative correlation between age and IRLS scores obtained after twelve months $(r=-0.9 p=0.0018)$, suggesting that older patients finished this period with fewer points in the questionnaire. A significant positive correlation between age and the percentage of improvement obtained ( $r=0.89$ and $\mathrm{p}=0.0026$ ) was also verified, suggesting that older patients had better evolution of motor symptoms than younger patients in the study period.

It is known that patients who begin to present RLS at more advanced ages in general tend to develop symptoms faster, not showing a clear distinction between age and severity of the clinical condition ${ }^{13}$. On the other hand, patients who begin to present RLS earlier in life tend to present the motor symptoms in an intermittent and insidious way in the beginning, but with progressive worsening, until 40 to 60 years-old when the symptoms may occur daily ${ }^{4}$. Most patients in this study apparently developed RLS symptoms above 50 years of age, which could have led to a rapid initial evolution, followed by a stabilization trend later. Such possibility has already been suggested in clinical course studies of patients with very tardive manifestation of RLS or Parkinson's disease ${ }^{6}$.

Serum ferritin levels showed marginally significant negative correlation with the IRLS scores after twelve months $(r=-0.7 p=0.052$ ). We believe that the small sample used in this study prevented us from analyzing properly this result. However, since the serum ferritin is usually considered a good marker of organic iron supplies ${ }^{14}$, it would be instigating to infer in this group that the pre-existence of good iron supply (brain) could be correlated with the favorable RLS development in the study period.

On the other hand, our results admit several considerations. Obviously, it is not possible to reject the inadequate filling of the IRLS or misunderstanding of its questions by the patients, despite the training and performance of the team responsible for the clinical research, since it is a common problem with the use of questionnaires in general. However, IRLS used in population studies have already demonstrated acceptable sensitivity and specificity degree ${ }^{15}$. The telephone interview has been used in the application of questionnaires in epidemiological research of RLS with no damage to the sensitivity or specificity of the instrument used ${ }^{15}$.

Finally, the small number of patients studied, which is a clear statistical disadvantage, and the absence of longterm evolution studies, prevented us from investigating the hypothesis that RLS could spontaneously improve or even disappear, either definitively or for many consecutive years and not only for "a few months". Obviously, these results need to be confirmed by studies that would include more individuals, higher number of variables rigorously examined (not just environmental but also biochemical and clinical ones) and duration above twelve months. Similarly, more studies on the clinical course of RLS should be conducted in order to better characterize the natural evolution of mild and moderate forms of RLS and to determine their true impact on the quality of life of patients, important factors to indicate the real need for treatment.

In summary, these data suggest that in this group of untreated RLS patients $(75 \%$ of individuals with the severe form), the natural evolution of the clinical condition in 12 months was favorable, with significant improvement measured through IRLS. This improvement is positively correlated with age and apparently not associated to any environmental changes or life habits.

\section{REFERENCES}

1. Ohayon MM, Roth T. Prevalence of restless legs syndrome and periodic limb movement disorder in the general population. J Psychosom Res 2002;53:547-554.

2. Grupo Brasileiro de Estudos em Síndrome das Pernas Inquietas (GBESPI). Restless legs syndrome: diagnosis and treatment: opinion of Brazilian experts. Arq Neuropsiquiatr 2007;65:721-727. 
3. Schapira AH. RLS patients: who are they? Eur J Neurol 2006;3:2-7.

4. Kushida CA.Clinical presentation, diagnosis, and quality of life issues in restless legs syndrome. Am J Med 2007;120(Suppl):S4-S12.

5. Hening W, Walters AS, Allen RP, Montplaisir J, Myers A, Ferini-Strambi L. Impact, diagnosis and treatment of restless legs syndrome (RLS) in a primary care population: the REST (RLS epidemiology, symptoms, and treatment) primary care study. Sleep Med 2004;5:237-246.

6. Garcia-Borreguero D, Egatz R, Winkelmann J, Berger K. Epidemiology of restless legs syndrome: the current status. Sleep Med Rev 2006;10:153-167.

7. Ferini-Strambi L. RLS-like symptoms: differential diagnosis by history and clinical assessment. Sleep Med 2007;8(Suppl):S3-S6.

8. Garcia-Borreguero D, Odin P, Schwarz C. Restless legs syndrome: an overview of the current understanding and management. Acta Neurol Scand 2004;109:303-317.

9. Zucconi M, Ferini-Strambi L. Epidemiology and clinical findings of restless legs syndrome. Sleep Med 2004;5:293-299.
10. Vergne-Salle $\mathrm{P}$, Coyral D, Dufauret K, Bonnet C, Bertin P, Trèves R. Is restless legs syndrome underrecognized? Current management. Joint Bone Spine 2006;73:369-373.

11. The International Restless Legs Syndrome Study Group. Validation of the International Restless Legs Syndrome Study Group rating scale for restless legs syndrome. Sleep Med 2003;4:121-132.

12. Walters AS, Hickey K, Maltzman J, et al. A questionnaire study of 138 patients with restless legs syndrome: the 'Night-Walkers' survey. Neurology 1996;46:92-95.

13. Allen RP, Picchietti D, Hening WA, et al. Restless legs syndrome: diagnostic criteria, special considerations and epidemiology: a report from the Restless Legs Syndrome Diagnosis and Epidemiology Workshop at the National Institutes of Health. Sleep Med 2003;4:101-119.

14. Allen R. Dopamine and iron in the pathophysiology of restless legs syndrome (RLS). Sleep Med 2004;5:385-391.

15. Hening WA. Subjective and objective criteria in the diagnosis of the restless legs syndrome. Sleep Med 2004;5:285-292. 